\title{
Usage of Energy Management System in Chemical Process Industry
}

R. MANIVASAGAM ( $\sim$ manivasagammn3@gmail.com )

K Ramakrishnan College of Engineering https://orcid.org/0000-0003-0987-5148

\section{Research Article}

Keywords: Energy sparing, Load sharing, Method control, SCADA checking

Posted Date: February 24th, 2021

DOI: https://doi.org/10.21203/rs.3.rs-261144/v1

License: (9) This work is licensed under a Creative Commons Attribution 4.0 International License. Read Full License 


\section{Abstract}

Primarily based trendy account energy the board and cycle robotization for a industry with proportion controls is projected. The energy the board is finished by 2 calculations particularly Energy potency rule and cargo Sharing rule. Varied siphons run in no heap or faithfully low burden condition, simply to forestall over-burdening. Utilizing the energy productivity calculation, No heap running of siphons is determined and killed once a amount delay. Every machine has its own restricted running life. In business to possess high dependableness reserve machines area unit likewise introduced nevertheless not used adequately. The heap sharing calculation plans equivalent running hours to order and first siphons. The cycle management is accomplished by mistreatment the inputs of transducers like stream, weight and temperature sensors to the framework, the signs area unit shipped off regulator and therefore the regulator cycle the signs and impel the elemental transfers to figure the cycle. The entire framework is incorporated and controlled through a SCADA framework .

\section{Introduction}

A shut circle management framework may be a bunch of mechanical or electronic gadgets that consequently manage a cycle to urge the perfect set focuses while not human intercession. Shut circle management frameworks seem otherwise in reference to open circle management frameworks, that need manual data. Circle is that the arrangement of kit components and programming control capacities engaged with estimating and dynamic a variable that controls a private cycle. Shut circle management frameworks area unit typically used in business applications for top dependable cycle management [1]. Fig 1 is that the Sulfuryl Chloride Chemical structure.

We have planned the framework considering a selected artificial plant. The cycle plant produces substance named sulfuryl chloride for calf restful before tanning. The cycle includes atomic number 17 , sulfur di-oxide and paraffin as crude material. The compound crude materials atomic number 17 and sulfur di-oxide area unit provided through passage. The cycle materials have to be compelled to blended in fume state for extraordinary authoritative therefore the artificial area unit ship off evaporator that may be a steam worked and therefore the necessary steam is non inheritable from the kettle. The substance segments should be blended in an exceedingly specific proportion for varied focus and fluctuate as indicated by the consumer desires. During this set up we've got designed up a totally robotized set up for programmed activity of that specific artificial plant. As a chunk of mechanization we've got likewise planned Associate in Nursing energy advancement calculations for power thrifty [2].

The shut circle framework is determined and unnatural by a unified SCADA framework. The concept of open and shut circle frameworks got in Fig.2. With the vision of business 4.0, we've got likewise designed up Associate in Nursing IOT pilot running model with chain of command based management [3]. 
In our paper we've got planned a computerized shut circle framework for energy the executives and cycle management for his or her framework style [4].

\section{Existing Framework}

In the current plant siphon management, Motors area unit unnatural by neighborhood management framework station utilizing ON or OFF order. There's no arrangement for mechanized transformation of siphons inflicting lopsided use of running and stay by siphons [5]. Likewise, there's no arrangement for preventing the siphon from ideal running. In the current plant live management, they turn out sulfurly chloride by utilizing the atomic number 17 , sulfur-di-oxide and paraffin in an exceedingly reactor. Transformation of atomic number 17 and sulphur dioxide from fluid state to vaporous state through period of time evaporator framework that is feed through a heater steam at express weight the entire framework and proportion management is controlled physically [6].

\section{Proposed Framework}

\subsection{Process management}

The cycle management is accomplished by introducing sensors like stream, weight and temperature sensors to screen the easy boundaries of the framework, the signs area unit ship off regulator and therefore the regulator cycle the signs and therefore the important point area unit checked and execute the important per the calculations [7]. The cycle is custom as follows, the stream from burrow is turned on utilizing a complicated valve and therefore the stream is decided utilizing the stream electrical device and answered to the Controller. Within the event of no stream even is that the valve is turned on Associate in Nursing alert is ring to demonstrate to administrator. The evaporator may be a steam warm type therefore the steam comes from a kettle [8]. The evaporator temperature is wellkept steady by utilizing a calculation created. The temperature is checked through trendy analysis Pt100 electrical device. To regulate the temperature with exactitude an easy value is employed to regulate the progression of steam to evaporator. A proportion management is employed to mix atomic number 17 and sulfur-di-oxide in express proportion. The proportion ought to be set by administrator that naturally controls the valves in like manner and sent the fume material to the reactor chamber [9].Fig.3 offers the sq. chart of the cycle. Through legitimate VFD management the backpressure building area unit dodged thus high safe is secure.

\subsection{Energy administration}

The energy the executives framework can take contributions from siphons like voltage, current, recurrence, running hours, ideal showing hours to no heap current by presenting Multi-work meter for every heap [10]. Plan of burden Sharing Running long stretches of electrical burdens area unit equally shared by the pre-characterized showing hours to programmable clocks within the energy the executives PLC and transformation naturally to the backup siphons on ending of predefined 
programmable clocks to ensure equivalent showing long stretches of obligation and stay to siphons [11]. The Energy Saving idea,The ideal running of the electrical burdens (no heap condition) distinguished by the force the executives framework PLC by No heap of components to be used [12].

Table1. Condition for 2 machines

\begin{tabular}{|l|l|l|}
\hline Machines & Timing & Status \\
\hline Motor M1 & 0-12 hrs. & M1 ON \\
& & M2 OFF \\
\hline Motor M2 & $12-24 h r s$ & M2 ON \\
& & M1 OFF \\
& & \\
\hline
\end{tabular}

On perceptive the Table1 we are able to get a review of the cycle occurring in an exceedingly day, aboard this on perceptive the Fig5, The progression of the cycle is processed. By this calculation we are able to management the force wastage and machine life time is genuinely swollen due legitimate run set up. The Fig5 clearly clarifies the progression of the energy the executives cycle that's completed within the whole cycle [13].

\section{Interfacing With lot}

The projected framework is unnatural by any convenience from any space through associating with the net .This should be potential by progressive system of management and security [14]. For exhibition we have a tendency to use second sight 8266 to regulate advanced sign through internet. Fig6 is that the diagram of IOT.

The IOT interfacing activity is finished utilizing the second sight 8266 Module with Open supply 10 interface. On the page we are able to read and management the operation.Fig7 clarifies the provision of second sight module with computer and Mobile phone.

\section{Conclusion}

Through mechanization the wastage of the fabric, energy, labor is diminished to a substantial level. The expense per cubic decimeter of the artificial compounds is likewise diminished. Improved facilitate of recognizability and management is accomplished which provides high shopper loyalty and customization. The most issue of this thought is that the administrator is unbroken from presentation to unsafe artificial substances used within the plant. The checking cycle is improved by any convenience and any spot handiness. The dependableness of this cycle is additional contrasted with gift set up.

\section{References}


1. Kulkarni VA, Katti PK, "Improvement of energy efficiency in industries by facility based energy management", Energy Automation and Signal (ICEAS) 2011 International Conference on, pp. 1-6, 2011

2. Rajendran Manivasagam and Velayutham Dharmalingam (2014, Vol) Power quality problem mitigation by unified power quality conditioner: an adaptive hysteresis control technique. International Journal of Power Electronics 6(4):403-425. DOI:10.1504/IJPELEC.2014.067442

3. Rajendran Manivasagam and Rajendran Prabakaran (2020) Power quality improvement by UPQC using ANFIS-based hysteresis controller. International Journal of Operational Research 37(2):174197. DOI:10.1504/IJOR.2020.105368

4. Wei jen lee,R.kenarangui "Energy management for motors,system and electrical equipment" IEEE Transactions on Industry Applications (Volume: 38, Issue: 2, Mar/Apr 2002)

5. Rajendran. M and Kumar GS G, "Comparative Analysis of PI / PID Controller for a Thermal Process Using PLC," 2018 International Conference on Recent Innovations in Electrical, Electronics \& Communication Engineering (ICRIEECE), Bhubaneswar, India, 2018, pp. 2839-2841, doi: 10.1109/ICRIEECE44171.2018.9008671

6. Giridhar Kini P, Sreedhar PN, "Efficient Utilization of Electrical Energy in Pumping Operations Based on Existing Conditions - A Case Study", TENCON 20052005 IEEE Region 10, pp. 1-4, 2005

7. Raghavi R, Manivasagam R, Paveethra SR,Modeling of a grid connected new energy vehicle charging station,International Journal of Applied Engineering Research (IJAER), Volume 10, Number 20 (2015),Special Issues, pp. 15870-15875

8. Rajendran M, Parthasarathy P, Anbumozhi R (2020) Robust Analysis of T-S Fuzzy Controller for Nonlinear System Using H-Infinity. In: Venkata Rao R, Taler J (eds) Advanced Engineering Optimization Through Intelligent Techniques. Advances in Intelligent Systems and Computing, vol 949. Springer, Singapore, pp 643-651. DOI https://doi.org/10.1007/978-981-13-8196-6_56

9. Curtis Parrot GK, Venayagamoorthy, "Real-Time Implementation of Intelligent Modeling and Control Techniques on a PLC Platform", Industry Applications Society Annual Meeting 2008. IAS '08. IEEE, pp. 1-7, 2008

10. Rajendran M (2020) Comparison of Various Control Strategies for UPQC to Mitigate PQ Issues. J Inst Eng India Ser B. https://doi.org/10.1007/s40031-020-00502-4

11. Richard SP et al 2020 IOP Conf. Ser.: Mater. Sci. Eng. 937 012002.doi:10.1088/1757899X/937/1/012002

12. Manivasagam Rajendran and Saranraj Rajendran, Wind Turbine Manufacturing Supply Chain,International Journal Of Scientific \& Technology Research ,Volume 9, Issue 03, March 2020, pp. $1278-1281$

13. R.Manivasagam and Kalpana.K, Speed Intensity of BLDC Motor with Fuzzy Base Peak Current Detection, International Journal Of Scientific \& Technology Research, Volume 9, Issue 03, March 2020, pp. 6021-6027 
14. Sushmitha R, Nithya R, Santhosh kumar T (April 2020) S. Sathiesh kumar, Dr. R.Manivasagam, Real Time Based Power Fluctuation Recorder Using Printer Interface. International Journal Of Scientific Technology Research Volume 9, Issue 04:84-87

\section{Figures}

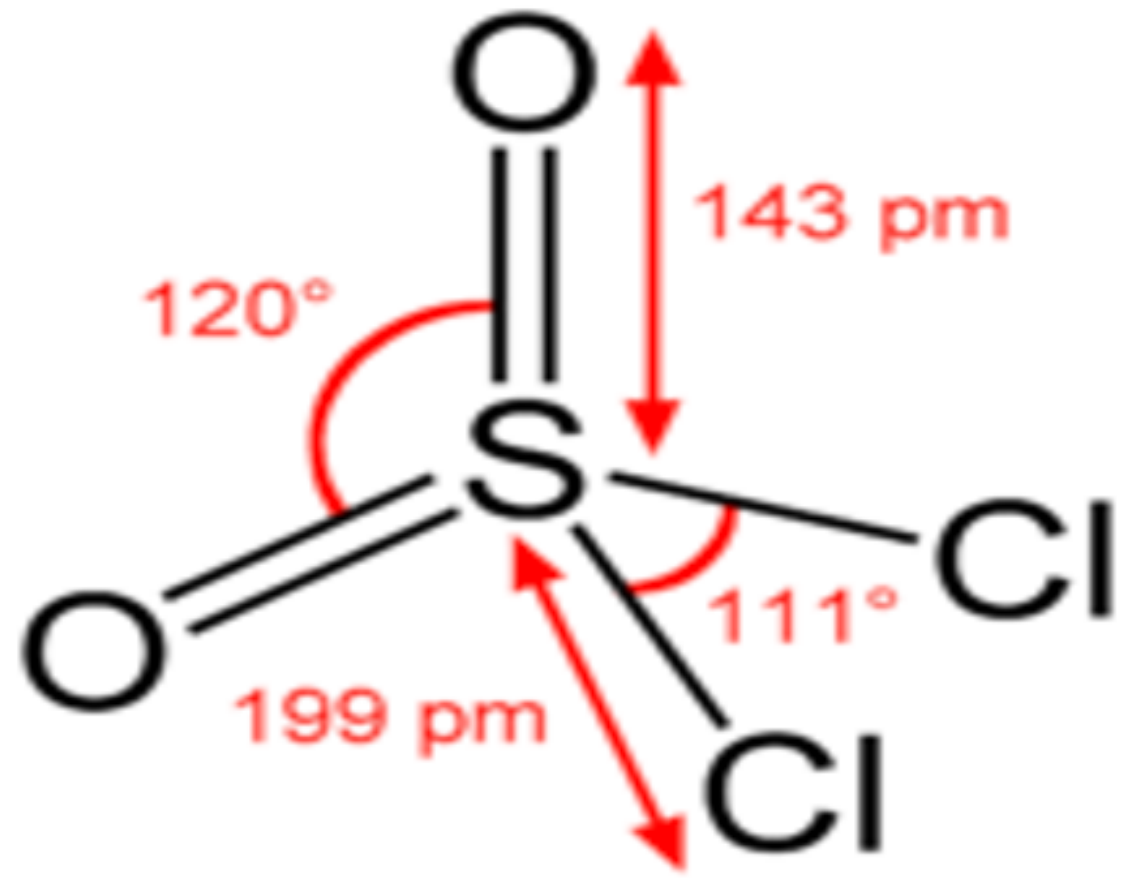

Figure 1

Structure of Sulfuryl Chloride 


\section{Open Loop Control System}

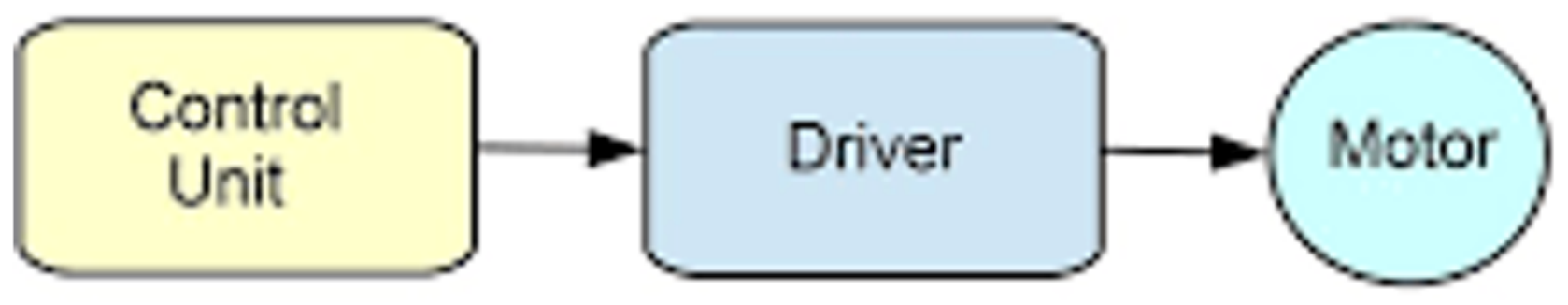

\section{Closed Loop Control System}

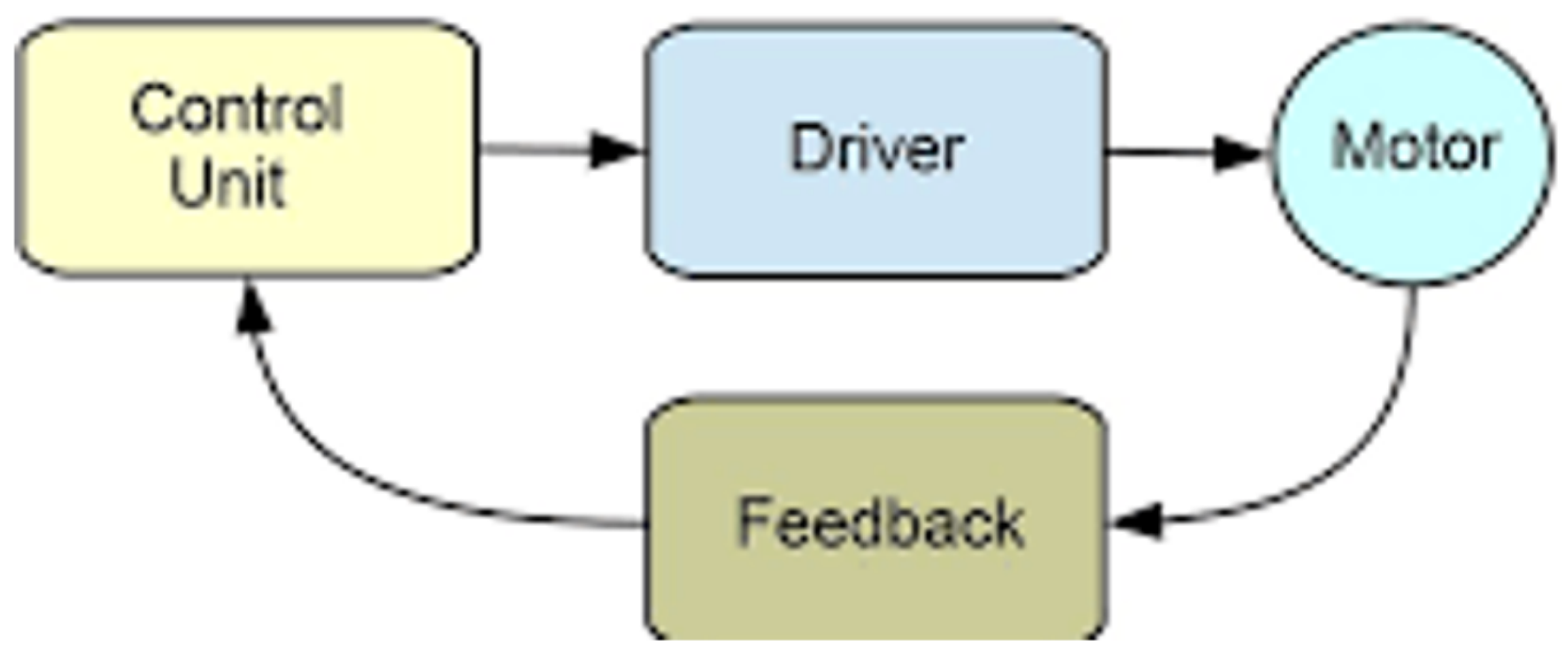

Figure 2

Open circle/ Shunt circle framework 


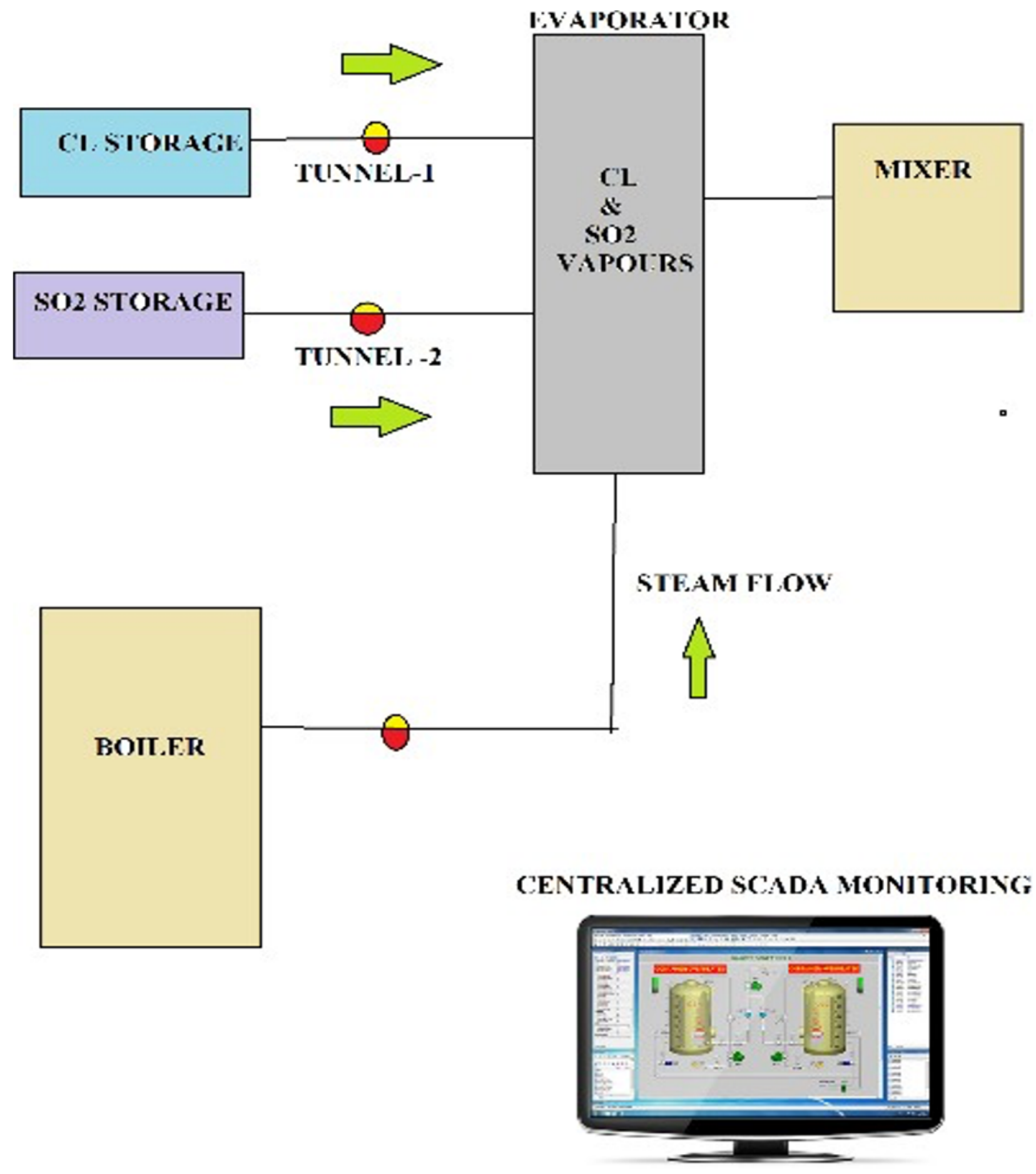

Figure 3

Sq. define of the cycle 


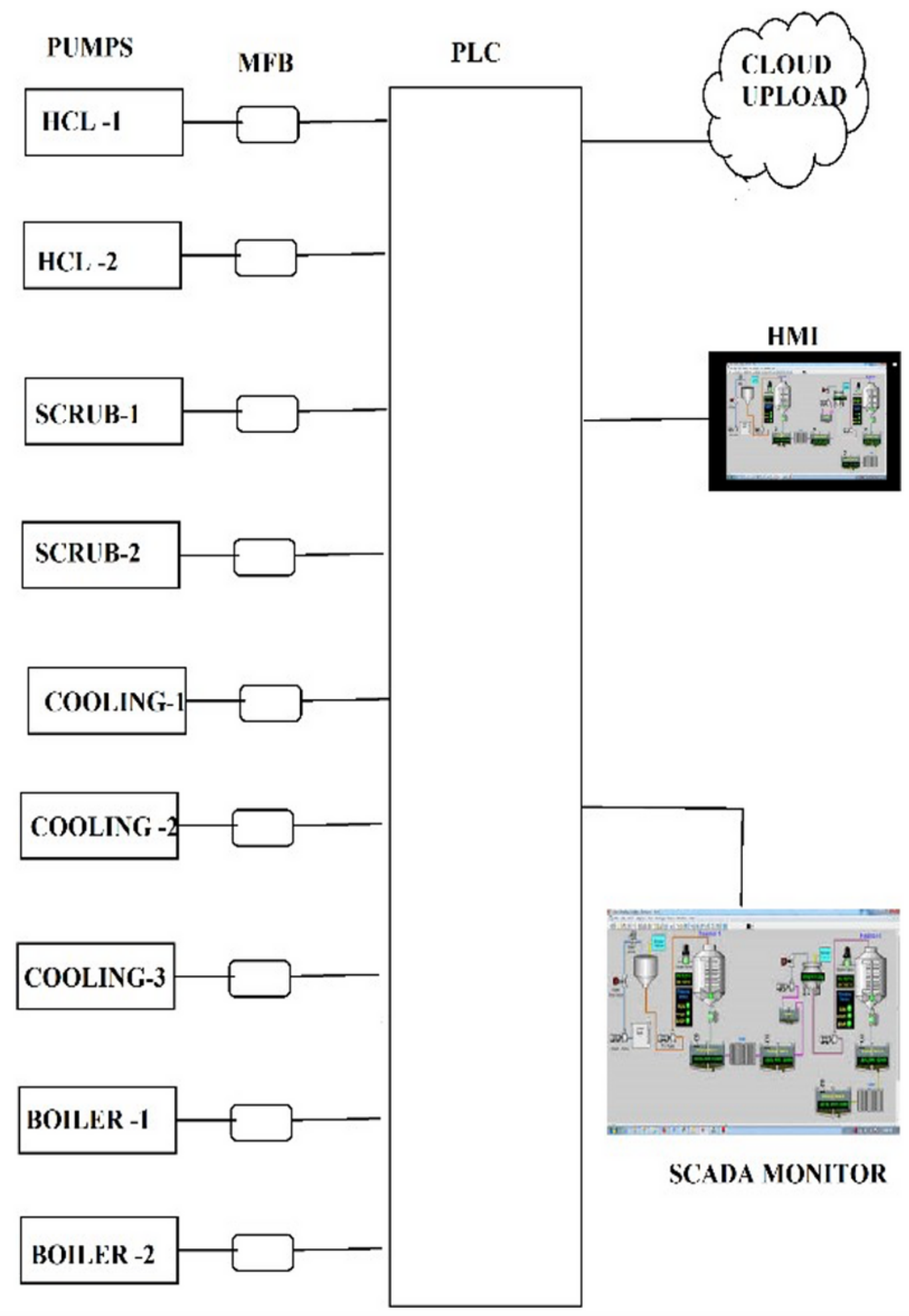

Figure 4

Compents used at the same time 


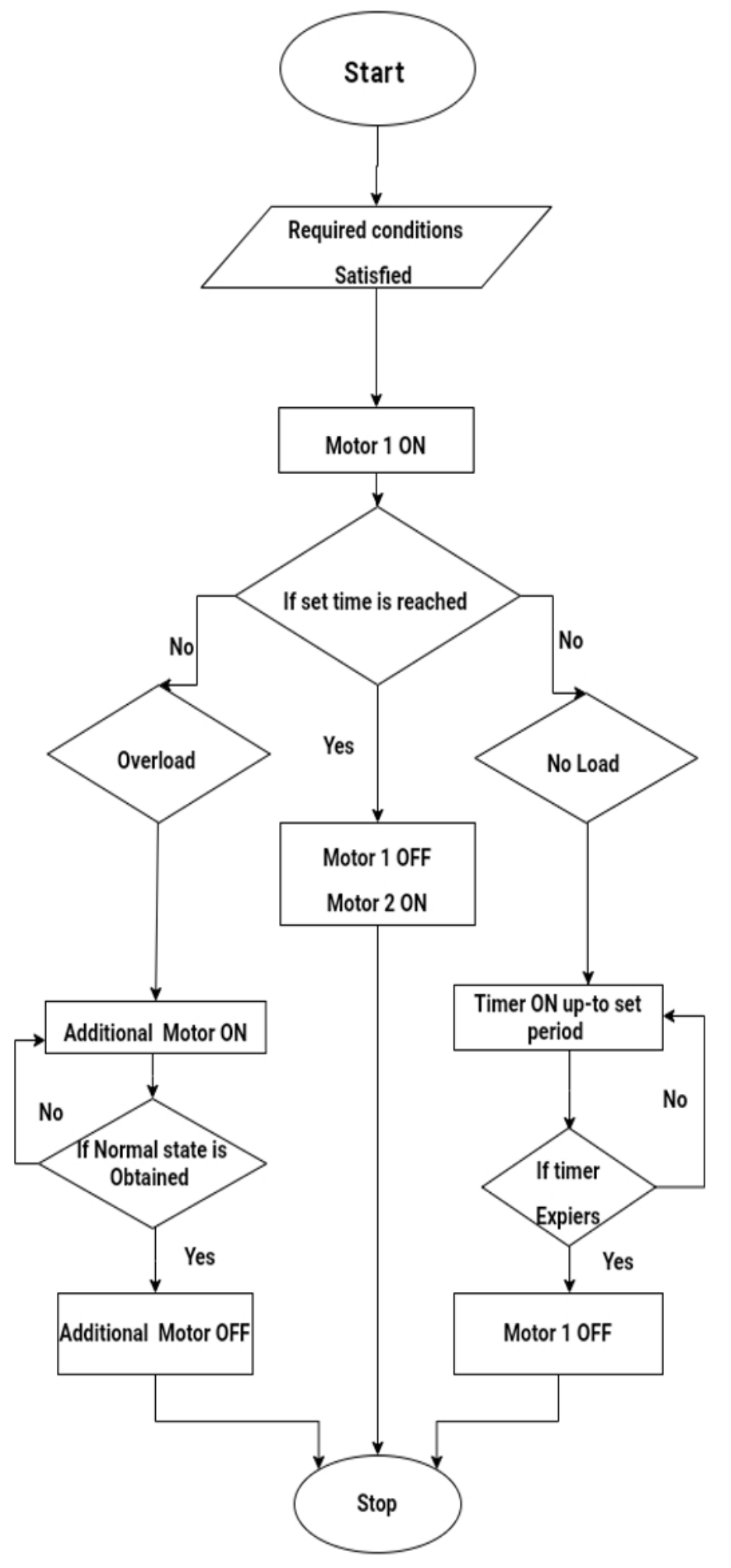

Figure 5

Flowchart of the energy the executives 


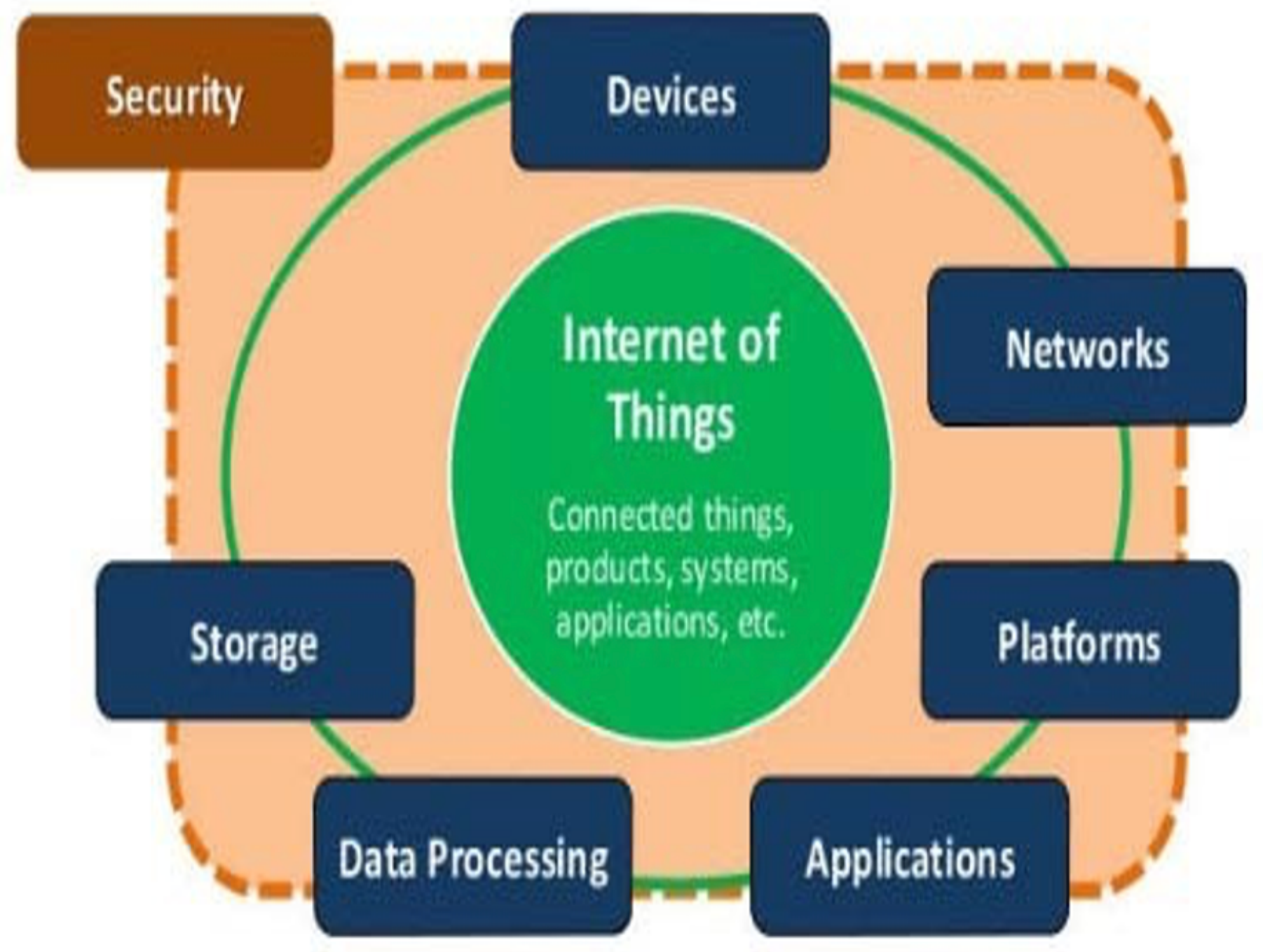

Figure 6

Overview Of IOT 


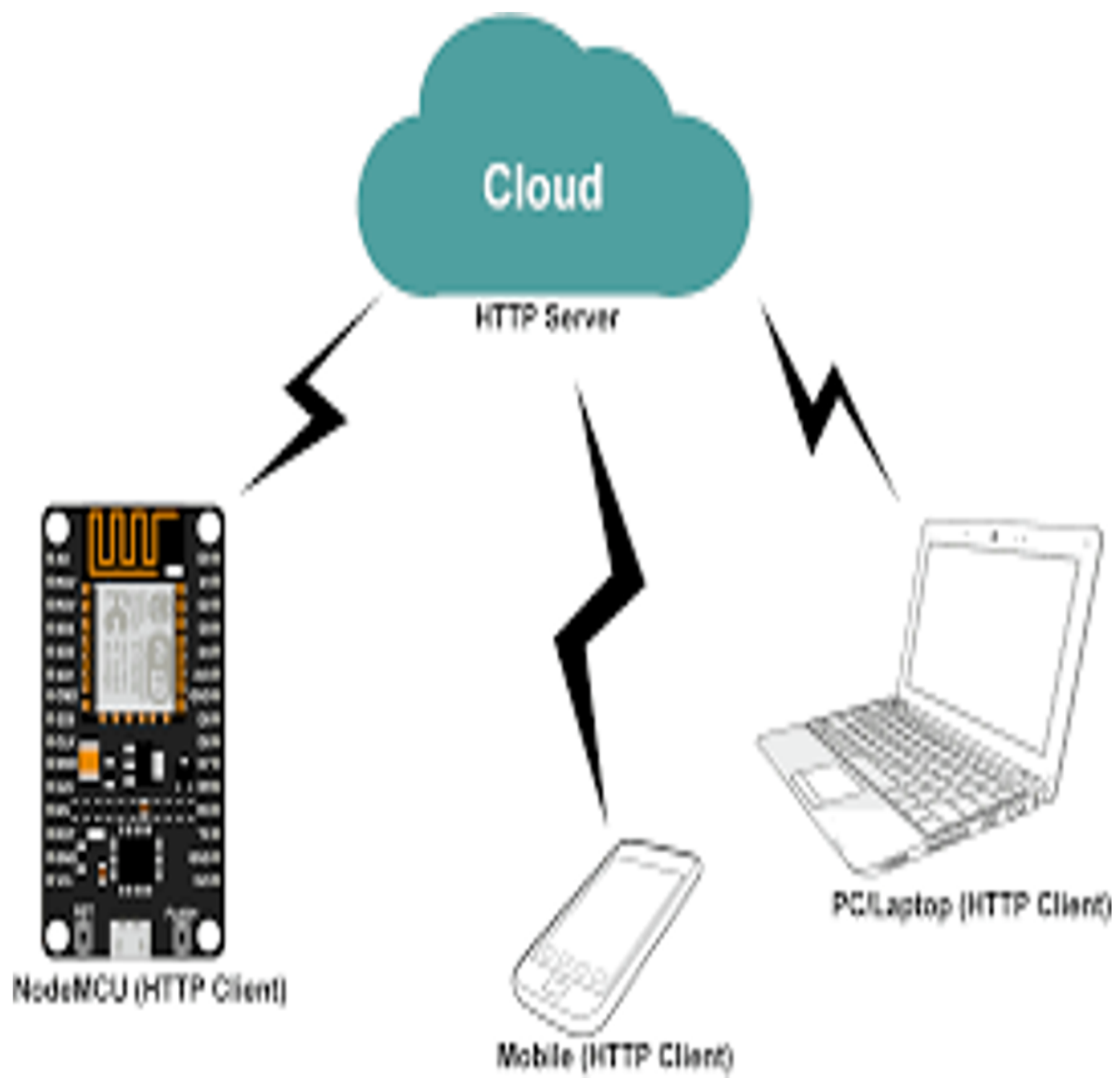

Figure 7

Interfacing second sight module

\section{Supplementary Files}

This is a list of supplementary files associated with this preprint. Click to download.

- GRAPHICALABSTRACTCONSERVATION.doc 